\title{
60. PRELIMINARY PALYNOLOGY OF PLEISTOCENE SEDIMENTS FROM DEEP SEA DRILLING PROJECT SITES 474 AND $479^{1}$
}

\author{
Les Sirkin, Earth Science Department, Adelphi University, Garden City, New York
}

\begin{abstract}
Nonarboreal pollen (NAP), mainly composites, grass, and Chenopodiaceae-Amaranthaceae (cheno-ams) dominate the Pleistocene record in this part of the Gulf of California. Arboreal taxa, such as pine and those from the forest, savannah and desert vegetation surrounding the Gulf, are also significant. With the exception of a zone of sprucejuniper in Hole 479, tentative pollen zones reflect minor changes in the representation of these groups.
\end{abstract}

\section{INTRODUCTION}

Few studies have been published on the pollen and spore stratigraphy of marine or coastal sediments of western Mexico. More is known about the distribution of modern pollen in the nearby marine environment. A summary of previous investigations appears in Habib et al. (1970). Of particular note is Muller's (1959) pioneering study, relating the distribution of modern pollen, especially Rhizophora mangle (red mangrove) in the marine sediments of western Venezuela, to fluvial and marine processes. Cross et al. (1966) provides extensive information on the dispersal of pollen and spores from the regional vegetation into the bottom sediments of the Gulf of California and relates their distribution to fluvial sources and marine currents. The authors also comment on the limited occurrence of Quercus (oak), Abies (fir), and red mangrove progressively away from known sources and on the relation of high pine values to the pollen sum and, thereby, to relative pollen statistics. They also described the vegetation zones surrounding the Gulf and indicated probable sources of pollen in the boreal, temperate, and tropical vegetational zones of the region. The authors identified certain potential indicator pollen, such as Simmondsia, and noted that many taxa characteristic of the regional vegetation zones (for example, the mangroves, Burseraceae and Fouquieriaceae) are only rarely encountered in the Gulf sediments. These considerations and the following stratigraphic determinations are relevant in interpreting the pollen data in this study.

Stratigraphic studies include Habib et al. (1970) who recognized four pollen zones in the Holocene sediments of the Middle American Trench. High pine percentages indicate cool and moist conditions occurring about 8000 to 9000 years ago, giving way to a warm, moist climate about 4000 years ago as indicated by higher oak, alder, and NAP values. Warm, dry climate, associated with a pine rise, succeeds around 3300 years ago. Most recently, there is a return to more moist conditions as indi-

\footnotetext{
${ }^{1}$ Curray, J. R., Moore, D. G., et al., Init. Repts. DSDP, 64: Washington (U.S. Govt. Printing Office).
}

cated by oak, red mangrove, and NAP increases in the uppermost sediments.

Other pollen studies in Mexico (Sears and Clisby, 1958) and in Central America (Martin, 1964; Tsukada and Deevey, 1967) generally associate the changes in relative abundance of certain arboreal and nonarboreal pollen as a whole to the climatic episodes of the Pleistocene epoch. Thus, oak and alder indicate warm and moist conditions, increases in NAP reflect cool and moist climates, and pine corresponds to dry intervals.

In the west Mexican coastal plain, Sirkin (1977) developed a pollen stratigraphy for lagoonal and estuarine sequences formed after postglacial sea level rise and barrier beach formation (Sirkin and Stuckenrath, 1977; Sirkin and Connally, 1977; Sirkin and Gilbert, 1978). Subsequent fluctuations in relative sea level, perhaps indicating tectonism and beach progradation, are interpreted from changes in mangrove representation; in the dominance of red mangrove, Laguncularia racemosa (white mangrove), and Avicennia nitida (black mangrove). According to the study of mangrove ecology presented by Lugo and Snedaker (1974), red mangrove predominates when the sea level is low but rising. White mangrove is more abundant during stable or lowering sea levels, and black mangrove predominates during the formation of paludal basins. Postglacial zones of vegetation, possible regional distribution of postglacial vegetation (e.g., a postulated expansion of highland (pine-oak) forests during cooler intervals), and possible indications of other climatic change are interpreted from variations in the pollen assemblages (Sirkin 1977; Sirkin and Stuckenrath, 1977; Sirkin and Connally, 1977; Sirkin and Gilbert, 1978). The pollen assemblages are composed of taxa directly related to the modern vegetational zones recognized by Shreve (1937), Gentry (1942), and Leopold (1950).

Because they share many taxa, the tropical forests of the piedmont, bajada, and coastal plain (i.e., the rain, tropical deciduous, and thorn forests) are not distinguishable in the pollen record in western Mexico, a conclusion supported by Fine (1977). But, significant variations in respective pollen assemblages may be interpreted for the highland forest, lowland forests com- 
bined, savannah and field, mangrove, and other coastal wetlands (Sirkin, 1977; Sirkin and Stuckenrath, 1977; Sirkin and Connally, 1977; Sirkin and Gilbert, 1978).

\section{PALYNOLOGY}

Thirty-eight samples were processed and analyzed for pollen content; two samples from Hole 474 were taken from Cores 1 and 2 (Fig. 1). Those taken from Hole 479 , however, represent a distribution of cores from top to bottom of the stratigraphic section. About 10 grams of sediment from each sample were processed using standard treatment schedules, including heavy liquid flotation to concentrate sufficient pollen for analysis. Pollen yields per gram of dried sediment were moderate, ranging from 5000 to 10,000 grains per gram. Pollen counts are on the order of 300 to 500 grains per slide, with only three sums falling significantly below 300 and one greatly exceeding 500 .

The pollen diagram (Fig. 2) summarizes the pollen counts and relative percentages, providing individual curves for the prominent taxa and arbitrarily grouping other AP and NAP taxa. Thus, the "Other AP"' curve represents mainly the temperate hardwood trees and shrubs, for example, Quercus (oak), Alnus (alder), Populus (poplar), and Celtis (hackberry); the "Mangroves" curve combines data for red, white, and black mangroves. The remaining APs are combined in the "Lowland Forests, etc." column and includes the prominent taxa counted in this study that represent the major vegetation zones of western Mexico as described in an earlier section. This latter group includes pollen of the Verbenaceae, Bignoniaceae, Papilionaceae, Ficus, Prosopis, Caesalpinaceae, Acacia, Bursera, Myrta-

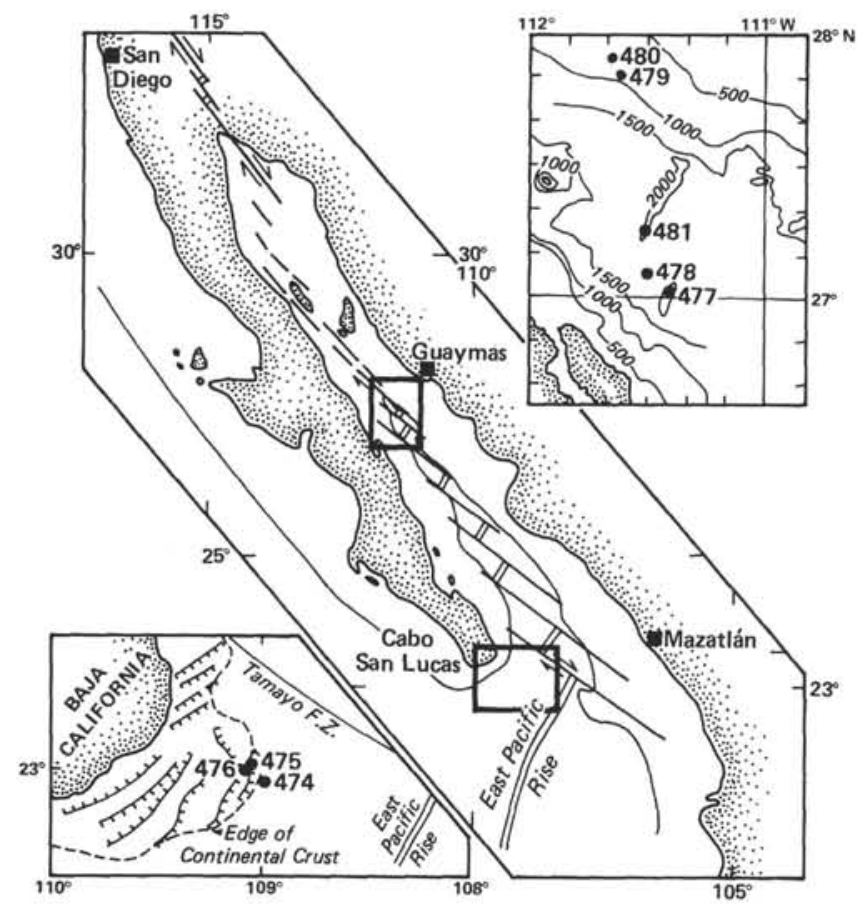

Figure 1. Location of Holes 474 and 479. ceae, Buxaceae, Euphorbaceae, Cactaceae, Agave, and Ephedra. In the NAP, Gramineae (grass), cheno-ams, Ambrosia (ragweed), and other composites-including Artemisia and high-spine types - are plotted separately, while all other NAPs, including unknowns, are plotted in one curve. Spores, hystrichosphaerids, and dinoflagellates are shown in one column ("Miscellaneous") according to abundance in the diagram. Percentages of AP and NAP are compared in the center column. Absolute pollen frequencies (APF) in grains per gram are also plotted in this column, with the scale at the base below the percentage scale. The APF values are connected by a solid line for emphasis.

\section{DISTRIBUTION OF POLLEN TYPES}

Throughout the cores, pine is the most abundant taxon in the AP, fluctuating from a high of $45 \%$ in Section 474-1-1, and $40 \%$ in Section 474-2-2 to a low of $12 \%$ in Section 479-45-2. In Hole 479, pine varies from a high of $31 \%$ to a low of $12 \%$ as indicated. Pine does seem to vary with the total AP percentages, a fact observed by Cross et al. (1966) and Habib et al. (1970), but it does not appear to be overrepresented with respect to total pollen. This may be due to consistently high values for the major NAP taxa. Pine may be one of the most prolific producers of pollen and one of the most readily transported forms, but NAPs such as grass, cheno-ams, and ragweed-derived from coastal plain sources-appear to be equally well distributed.

Picea (spruce) pollen, a definite boreal form, occurs in only one sample (from 479-17-3). Alternatively, Juniperus (juniper) occurs in almost all samples and peaks in Sections 479-18-2 and 479-17-3. Oak, generally associated with pine in the highland forests, rarely attains more than $3 \%$. Poplar is equally subdued, with its greatest representation in the basal samples (479-47-5 to $479-45-$ 2). Hackberry also occurs in the microflora and is more common in the upper half of Hole 479.

The mangroves are quite rare in these sediments, with black mangrove the most frequently encountered. Red and white mangrove, occurring in moderate amounts in the coastal mangrove sediments of Sinaloa and Nayarit (Sirkin, 1977; Sirkin and Stuckenrath, 1977; Sirkin and Connally, 1977; Sirkin and Gilbert, 1978), are not carried into the basin in any quantity. In the lowland forest grouping of taxa, Bignoniaceae (for example, the Tecoma type of pollen), Verbenaceae, and Papilionaceae are best represented in the record, although not significantly. Acacia and Caesalpina are rare. Prosopis (mesquite) is more consistently represented but is not zonally significant, and Cactaceae occur only infrequently. Ephedra is nearly as well distributed as oak in the marine sediments, but other AP, such as Bursera, Ficus, and Rosaceae, are uncommon. Shrubs, such as Larrea (creosote bush) in the Zygophyllaceae indicate a long-travelled taxon of the chapparal from north of the Gulf of California as does Simmondsia, an evergreen shrub from the northern Baja (Cross et al., 1966).

The NAP in these sections consistently represent over $50 \%$ - and in all but four samples, over $60 \%$ - of the pollen. The prominent taxa of the NAP are ragweed 


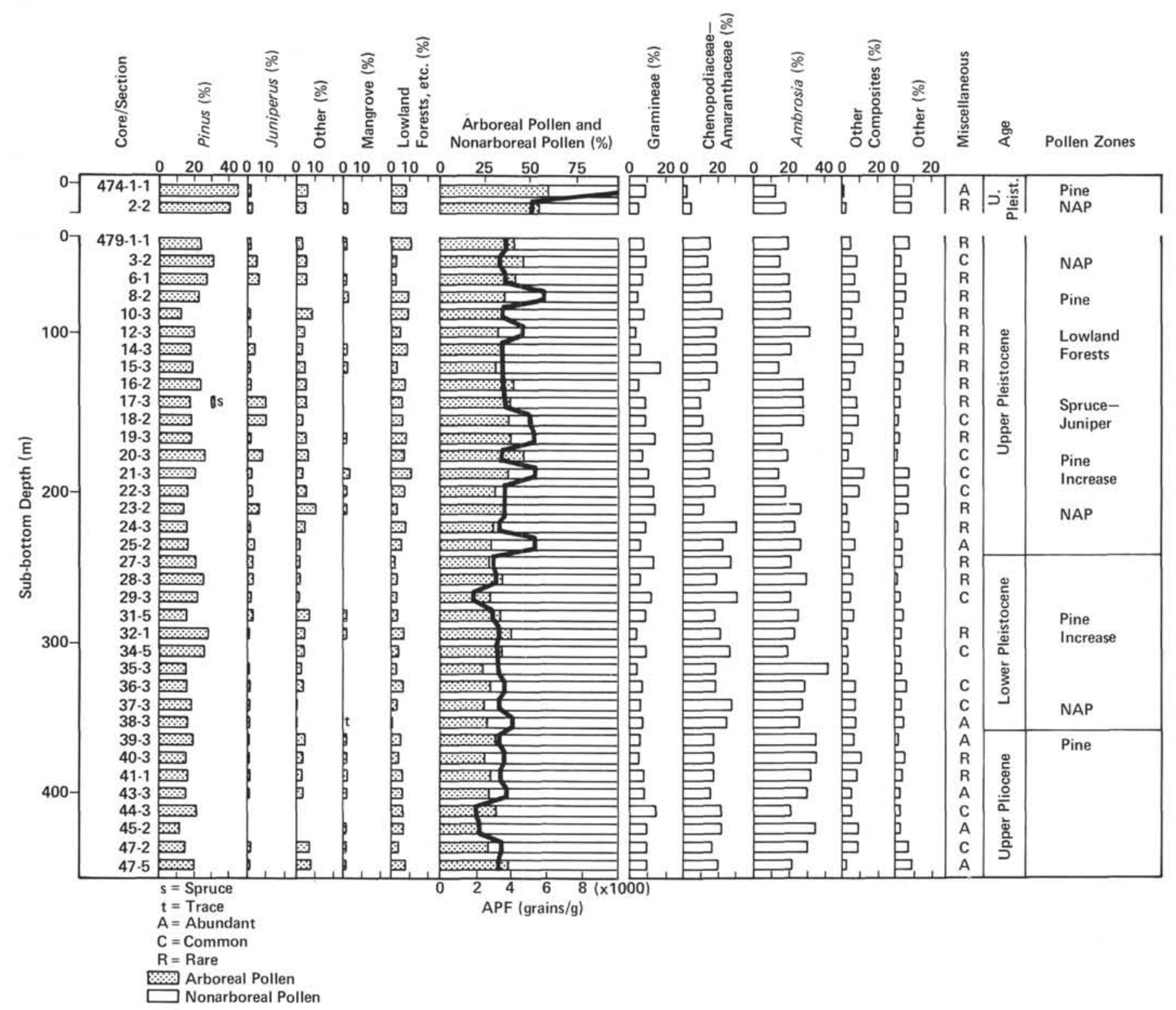

Figure 2. Pollen diagram for Holes 474 and 479.

(generally the most abundant form), the cheno-am group, grass, and other composites. They all maintain moderate- to moderately high representation and appear to vary independently of any one taxon, including pine. Ragweed peaks in Section 479-35-3 with $43 \%$, and cheno-ams seem more plentiful between two highs from 479-29-3 to 479-24-3 in Hole 479. Grass varies between a high of $18 \%$ and a low of $4 \%$; but no pattern emerges from this distribution. The other NAPs are scattered through the record but mainly are forms derived from coastal environments around the gulf. Some of the herbaceous forms would occur in savannahs or lowland forests, but others probably originate in coastal wetlands and salt pans. Salicornia (glasswort) is a probable component of the cheno-am group and is common in salt pans.

Spores occur in most samples but only in trace amounts when compared to the pollen sum. They in- clude Polypodiaceae (fern) and Sphagnum spores with occasional Selaginella, Cyathaceae, and Cretaceous forms. Hystrichosphaerids also appear, as do Gonyaulax type of dinoflagellates, the latter more abundantly between Sections 479-47-5 and 479-37-3 and particularly in 479-43-3 and 479-38-3.

Staining indicates relatively the age of polleniferous sediments in a given core (Stanley, 1966). A record of staining differences in samples from Hole 479 shows that variations in staining of pollen grains does occur over the extensive Pleistocene record of the cores. For example, from 479-47-5 to 479-31-5, pollen are generally unstained, or, as in 479-43-1, 479-40-3, 479-37-3, and 479-34-3, the microflora is largely unstained except for a very light stain on a few pollen. Between 479-29-3 and 479-19-3, pollen are lightly stained, and above 479 $18-2$, they are well stained; the uppermost samples in Holes 479 and 474 are very well stained. In all samples, 
the same staining procedure (suspending pollen residues in gentian-violet-stained glycerin gelatin in a warm water bath for 15 minutes) was used.

\section{DISCUSSION OF THE POLLEN STRATIGRAPHY}

The distribution of pollen throughout the samples from Hole 479 is quite even, with very few, if any, surprises or reversals in the dominant taxa. Unlike the Hole 474 spectra, there are, for example, no zones dominated by pine, although pine does increase. The evenness applies to both AP and NAP taxa and groupings. A major reservation to zoning this record is the spacing of the samples every 10 meters. With a scale of roughly (greater than) 200,000 years per 100 meters, or 2000 $\mathrm{y} . / \mathrm{m}$, sediment and pollen indicating climatic fluctuations could be bypassed easily.

In the lower Pleistocene sediments, between Sections 479-47-5 and 479-27-3, the NAP, particularly ragweed and cheno-ams, predominate, with the NAP representing as much as $77 \%$ of the pollen at Section $479-45-2$. From Sections 479-45-2 to 479-44-3, there is also a drop in APF values and the pine minimum. The sediment between 479-47-5 and 479-44-3 does not contain any Tertiary index pollen that might confirm a possible Pliocene age for the section below Core 44 (as suggested by Kelts, personal communication, 1979). Perhaps additional samples in this interval should be studied. The APF also has fewer peaks in the lower Pleistocene section than in the upper Pleistocene, but ragweed percentages vary inversely with the APF, with greater values occurring in the lower Pleistocene section. An increase in pine between 479-34-5 and 479-28-3 might also be significant, although NAP remains dominant.

Similarly (with but one exception), the upper Pleistocene section of the record has few significant changes. Several spruce pollen grains ( $2 \%$ of the sum) were found in Section 479-17-3. Furthermore, juniper and ragweed increase in Sections 479-18-2 and 479-17-3, and many of the "Mangrove," "Lowland Forests, etc."' taxa, as well as the "Other NAP," drop out briefly at $479-18-2$. Between 479-20-3 and 479-17-3, APF values increase, and the grass count rises to 84 grains $(15 \%)$ in Section 479-18-2. These data, therefore, appear to represent a potential spruce-juniper pollen zone. The fact that these changes take place in a limited sample interval (mainly in 479-17-3), supports the idea that the method of sampling may have missed the true extent and composition of the interval. Perhaps additional samples will be available to reveal the details of this event.

Above this level, increases occur in pine and "Lowland Forests, etc. pollen" with slight rises in the AP overall. The zonations proposed by Habib et al. (1970) and Sirkin (1977) are not apparent here because of the sampling interval in the upper 0 to 20 meters of the core where the relevant data might be expected.

\section{CONCLUSIONS}

1. The long-term distribution of pollen from the vegetation surrounding the Gulf of California and the apparent continuity of the dominant pollen throughout the record with little change in composition provide a seemingly uneventful record of Pleistocene vegetational and climatic change. Perhaps the overall changes in regional vegetation that might be apparent in the onshore record are not available in the marine record of this basin. Vegetational zone complexities, pollen production, transport, and deposition may develop a more homogeneous pollen record. Although most of the pollen counted are not corroded, it is possible that a few taxa more sensitive to climatic change may have been lost in transit or during diagenesis. It may also be that the seemingly minor fluctuations in pine and oak actually have some zonal significance.

2. Changes in the pollen record, noted by general increases and decreases of the same taxa, NAP dominance, and APF values, may be significant. The only clearly unique event is the appearance of spruce in one sample. Spruce and the other minor fluctuations in pollen occurring at that level might be of zonal significance and actually indicate the occurrence of a glacial interval. Alternatively, an influx of volcanic ash has also been noted at that level. Could the appearance of spruce reflect merely a change in wind direction associated with a volcanic eruption?

3. The method of sampling consistently bypasses the intervals of greatest change-or the investigator has missed the subtle differences masked by the, apparently, uneventful record.

\section{ACKNOWLEDGMENTS}

I gratefully acknowledge the critical reviews of Dr. Linda Heusser and Dr. Constance Sancetta. The research in western Mexico is supported by the National Science Foundation grant EAR 7724349.

\section{REFERENCES}

Cross, A. T., Thompson, G. G., and Zaitzeff, J. B., 1966. Source and distribution of palynomorphs in bottom sediments, southern part of Gulf of California. Mar. Geol., 4:467-524.

Fine, B., 1977. Vegetation and modern pollen spectra in Sinaloa and Nayarit, Mexico [M.S. thesis]. University of Arizona.

Gentry, H. S., 1942. Rio Mayo Plants. Carnegie Inst. Wash. Publ. 527: Washington, D.C.

Habib, D., Thurber, D., Ross, D., et al., 1970. Holocene palynology of the Middle America Trench near Tehuantepec, Mexico. Geol. Soc. Am. Mem., 126:233-261.

Leopold, A. S., 1950. Vegetation zones of Mexico. Ecology, 31:507518.

Lugo, A. E., and Snedaker, S. C., 1974. The ecology of mangroves. Ann. Rev. Ecol. Syst., 5:39-64.

Martin, P. S., 1964. Paleoclimatology and a tropical pollen profile. 6th International Congress Quaternary Report, Warsaw, 1961, pp. 319-323.

Muller, J., 1959. Palynology of recent Orinoco delta and shelf sediments. Micropaleontology, 5:1-32.

Sears, P. B., and Clisby, K. H., 1955. Palynology in southern North America, Part IV: Pleistocene climate in Mexico. Geol. Soc. Am. Bull., 66:521-530.

Shreve, F., 1937. Lowland vegetation of Sinaloa. Bull. Torrey Bot. Club, 64:605-613. 
Sirkin, L., 1977. Late Pleistocene palynology and stratigraphy of the west Mexican coastal plain. [paper presented at the X INQUA Congress, Birmingham]. (Abstract)

Sirkin, L., and Connally, G. G., 1977. Quaternary geomorphology and environments of the west Mexican coastal plain. Geol. Soc. Am. Abstract with Programs, 9:1178-1179. (Abstract)

Sirkin, L., and Gilbert, D., 1978. Holocene palynology of the west Mexican coastal plain 1. The Teacapan estuary region. Am. Assoc. Stratigraphic Palyn., Abstract with Programs, pp. 35-36. (Abstract)
Sirkin, L., and Stuckenrath, R., 1977. Late Pleistocene stratigraphy and palynology of the west Mexican coastal plain. Geol. Soc. Am. Abstract with Programs, 9:73-74. (Abstract)

Stanley, E. A., 1966. The problem of reworked pollen and spores in marine sediments. Mar. Geol., 4:397-408.

Tsukada, M., and Deevey, E. S., 1967. Pollen analysis from four lakes in the southern Maya area of Guatemala and El Salvador. In Cushing, E. J., and Wright, H. E. Jr. (Eds.), Quaternary Paleoecology: New Haven (Yale University Press), pp. 303-332. 